\title{
La intervención estatal en el mundo del trabajo: la aplicación de la Ley de Descanso Dominical en el centro bonaerense (Tandil, 1917-1930)*
}

LuCIANo OSCAR BARANDIARÁN

Afiliado institucionalmente al Consejo Nacional de Investigaciones Científicas y Técnicas-CONICET (Argentina). Correo electrónico: cleido7@yaoo.com.ar. El autor es doctor en Historia de la Universidad Nacional del Centro de la Provincia de Buenos Aire. Entre sus publicaciones recientes tenemos: en coautoría "Política y sociabilidad barrial: la memoria en torno a las veladas socialistas en el Barrio de la Estación de Tandil durante el período de entreguerras" Aletheia. Revista de la Maestría en Historia y Memoria de la Facultad de Humanidades y Ciencias de la Comunicación, Vol. 5 No. 10 (2015) y "El accidente fatal del trabajador rural y la justicia en el centro de la provincia de Buenos Aires (1935-1947)", revista Res Gesta, No. 51 (2015). Entre sus temas de interés están Debates políticos y actores sociales en la construcción de la ciudadanía argentina (1860-2010).

\footnotetext{
Recibido: 23 de agosto de 2016

Aprobado: 8 de noviembre de 2016

Modificado: 12 de enero de 2017

Artículo de investigación científica
}

DOI: http://dx.doi.org/10.15648/hc.31.2017.7

Este artículo forma parte del proyecto: "Estado y Sociedad en la Argentina del siglo XX. Mediación e intervención en las relaciones laborales: el accionar del Departamento del Trabajo de la Provincia de Buenos Aires (1917-1945)" financiado por el Consejo Nacional de investigaciones Científicas y Técnicas-CONICET (Argentina).

Esta publicación está bajo una licencia Creative Commons Reconocimiento-NoComercial 4.0 
La intervención estatal en el mundo del trabajo: la aplicación de la Ley de Descanso Dominical en el centro bonaerense (Tandil, 1917-1930)

\title{
Resumen
}

El objetivo es analizar en el ámbito rural y urbano del centro bonaerense el accionar del Departamento del Trabajo de la Provincia de Buenos Aires (DPT), a través de la aplicación de la Ley de Descanso Dominical. A partir de un estudio de caso, se pretende observar las relaciones establecidas entre aquella repartición provincial y la sociedad local del partido de Tandil y su zona de influencia. Se estudian las formas iniciales de vinculación de los funcionarios provinciales y las problemáticas obreras del interior bonaerense, y las reacciones causadas por la intervención de los funcionarios del DPT.

Palabras claves: Legislación laboral, Departamento del Trabajo de la Provincia, trabajo rural, trabajo urbano, centro bonaerense.

State intervention in the working world: The application of the Sunday Rest Law in the center of Buenos Aires (Tandil, 1917-1930)

\begin{abstract}
The purpose of this article is to analyze, in the rural and urban areas of the center in Buenos Aires, the actions of the Department of Labor of the Province of Buenos Aires (DPT), through the application of the Sunday Rest Law. Based on a case study, it is intended to observe the relations established between that provincial division and the local society of the Tandil party and its area of influence. It is studied the initial forms of provincial officials' labor links and Buenos Aires workers issues as well as the reactions caused by the actions of DPT officials.
\end{abstract}

Keywords: Labor legislation, Department of Labor of the Province, rural work, urban work, Buenos Aires center.

A intervenção estatal no mundo do trabalho: a aplicação da lei do Descanso dominical no centro de Buenos Aires (Tandil,1917-1930)

\section{Resumo}

O objetivo é analisar no âmbito rural y urbano do centro de Buenos Aires, a ação do Departamento do Trabalho da Província de Buenos Aires (DPT), através da aplicação 
da lei do Descanso dominical. A partir de um estudo do caso, pretende-se observar as relações estabelecidas entre esta repartição provincial e a Sociedade local do partido de Tandil e sua zona de influência. Estudam-se as formas iniciais de vinculação dos funcionários da província, a problemática operária do interior de Buenos Aires, e as reações causadas pela intervenção dos funcionários do DPT.

Palavras-chaves: Legislação Trabalhista, Departamento do trabalho da Província, trabalho rural, trabalho urbano, centro de Buenos Aires.

L'intervention de l'État dans le monde du travail: l'application de la Loi du Repos Dominical dans le centre de la province de Buenos Aires (Tandil, 1917-1930)

\section{Résumé}

Le but est d'analyser dans le domaine rural et urbain du centre provincial la gestion du Département du Travail de la province de Buenos Aires (DPT), à travers l'application de la Loi du Repos Dominical. À partir d'une étude de cas, on prétend repérer les relations instaurées entre cette division provinciale et la société locale du parti de Tandil et sa zone d'influence. On étudie les formes initiales d'embauche des fonctionnaires provinciaux et les problématiques ouvrières de l'intérieur de la province de Buenos Aires et les réactions provoquées par l'intervention des fonctionnaires du DPT.

Mots clés: Législation du travail, Département du Travail de la Province, travail rural, travail urbain, centre de la province de Buenos Aires.

"En el extenso territorio de la provincia, vive y se desarrolla una población más numerosa que la existente en la Capital Federal. La cantidad de trabajadores en la misma, por consiguiente, es proporcionalmente mayor, también diseminada en ciudades, pueblos y campos, entregada a ocupaciones fabriles, comerciales, agrícolas, ganaderas". Bernardo Aineseider, $1927^{1}$

1 Provincia de Buenos Aires, Departamento del Trabajo de la Provincia de Buenos Aires 1922-1926 (La Plata: Taller de Impresiones Oficiales, 1927), 8. Bernardo Aineseider fue Director del DPT entre 1922 y 1930. 


\section{INTRODUCCIÓN}

La provincia de Buenos Aires ha ocupado y ocupa un lugar central en Argentina por su preeminencia económica y demográfica, siendo el motor del crecimiento agroexportador que desde fines del siglo XIX sostuvo el país. Por otro lado, buena parte de la historia argentina se escribió con base en lo que aconteció allí, al coincidir al menos hasta 1880 la administración estatal nacional y la provincial en el mismo espacio. Eso explica, como ha sido señalado recientemente, que la historiografía bonaerense haya tenido una identidad difusa; por ende, escribir sobre problemas propios de la historia bonaerense implica hacerlo considerando las semejanzas y diferencias entre los procesos sociales que allí acontecieron con respecto a lo sucedido en la capital federal del país, la ciudad de Buenos Aires ${ }^{2}$.

Si la historiografía provincial fue identificada con la nacional, al punto de ser dos relatos casi inseparables ${ }^{3}$, un segundo obstáculo en el campo de los análisis sobre las políticas sociales ha sido el desinterés por su tratamiento. Posiblemente el mejor ejemplo de ello sea el estudio de las políticas laborales. Hasta hace relativamente poco tiempo, la mayor parte de los trabajos sobre el tema se habían centrado en la historia del Departamento Nacional del Trabajo (DNT) y sus vinculaciones con organismos estatales laborales posteriores (la Secretaría de Trabajo y Previsión y el Ministerio de Trabajo), identificados con el acceso de Perón al poder (1943-1955);

2 Juan Manuel Palacio, "La provincia de Buenos Aires en la historia y en la historiografía", en Historia de la provincia de Buenos Aires. Tomo I, Población, ambiente y territorio, eds. Hernán Otero (Buenos Aires: Unipe-Edhasa, 2012), 9.

3 Juan Manuel Palacio, La provincia de Buenos Aires, 23.

4 La historiografía argentina se ha ocupado en profundidad del DNT. Se han contemplado, entre otras dimensiones, su vinculación con la implementación de políticas sociales en Argentina: Daniel Lvovich y Juan Suriano (eds.), Las políticas sociales en perspectiva histórica. Argentina, 1870-1952 (Buenos Aires: Prometeo-UNGS, 2006); Mirta Lobato y Juan Suriano, "Introducción. Trabajo, cuestión social e intervención estatal", en La sociedad del trabajo. Las instituciones laborales en la Argentina (1900-1955), comp. Mirta Lobato y Juan Suriano (Buenos Aires: Edhasa, 2013), 9-53. La etapa inicial del organismo: Néstor Auza, "La política del Estado en la cuestión obrera al comenzar el siglo XX: El Departamento Nacional del Trabajo, 1907-1912", Revista de Historia del Derecho No. 15 (1987): 101-140; Germán Soprano, "Haciendo inspección. Un análisis del diseño y aplicación de la inspección laboral por los funcionarios del Departamento Nacional del Trabajo (1907-1914)", En Un estado con rostro humano. Funcionarios e instituciones estatales en Argentina (desde 1880 a la actualidad), eds. Ernesto Bohoslavsky y Germán Soprano (Buenos Aires: Prometeo, 2010), 85-120. 
o con antecedentes subnacionales de esa experiencia, como el gobierno bonaerense de Fresco entre 1936 y $1940^{5}$. Ese desinterés ha comenzado a revertirse al analizarse las políticas laborales desarrolladas desde, en y por las provincias en las décadas anteriores al surgimiento del peronismo ${ }^{6}$.

Esta nueva perspectiva en torno al origen de las políticas laborales a nivel federal ha significado un avance, pero necesita continuar profundizándose. En principio, con la excepción de la región pampeana y las provincias de Mendoza y Tucumán, se necesitan más estudios sobre la implementación de aquellas políticas en las restantes provincias y los Territorios Nacionales durante la primera mitad del siglo XX. Además, la mayor parte de los estudios existentes sobre los Departamentos del Trabajo a nivel subnacional han analizado lo que aconteció en sus sedes centrales ubicadas en

Las tendencias políticas e ideológicas de sus funcionarios, al igual que las influencias internacionales en torno a su creación: Eduardo Zimmermann, Los liberales reformistas. La cuestión social en la Argentina 1890-1916 (Buenos Aires: Sudamericana-Universidad de San Andrés, 1995); Juan Suriano, "El mundo como un taller de observación. La creación del Departamento Nacional del Trabajo y las influencias internacionales", Revista de Indias Vol. LXXIII No. 257 (2013): 107-130; Laura Caruso, "La política laboral argentina en la inmediata posguerra: una perspectiva internacional, 1907-1925", Revista Relaciones Vol. 35 No. 138 (2014): 11-43. La persistencia de su "proyecto fundacional": Germán Soprano, "El Departamento Nacional del Trabajo y su Proyecto de Regulación Estatal de la Relación Capital-Trabajo en Argentina: 1907-1943”, en Argentina: trabajadores entre dos guerras, comp. José Panettieri (Buenos Aires: Eudeba, 2000), 31-53; Germán Soprano, "Del Estado en singular al Estado en plural. Contribución para una historia social de las agencias estatales en la Argentina”, en Cuestiones de sociología No. 4 (2007), 19-48. La trayectoria del DNT durante el radicalismo: Enrique Garguin, "Relaciones entre Estado y sindicatos durante los gobiernos radicales, 1916-1930", en Argentina: trabajadores entre dos guerras, comp. José Panettieri (Buenos Aires: Eudeba, 2000), 87-117; Juan Suriano, "El Departamento Nacional del Trabajo y la política laboral durante el primer gobierno de Hipólito Yrigoyen", en Los saberes de Estado, comps. Mariano Ben Plotkin y Eduardo Zimmermann (Buenos Aires: Edhasa, 2012), 35-62. Su transformación en la Secretaría de Trabajo y Previsión hacia 1943: Daniel Campione, Orígenes estatales del peronismo (Buenos Aires: Miño y Davila, 2007), 109-113; María Luciani, "La etapa formativa de la Secretaría de Trabajo y Previsión (1943-1946): Primeros pasos organizativos y figuras relevantes", Anuario del Instituto de Historia Argentina No. 14 (2014): 1-16.

5 María Dolores Béjar, El régimen fraudulento. La política en la provincia de Buenos Aires, 19301943 (Buenos Aires: Siglo XXI Editores, 2005), 139-186; Rafael Bitrán y Alejandro Schneider, El gobierno conservador de Manuel A. Fresco en la provincia de Buenos Aires (1936-1940) (Buenos Aires: CEAL, 1991), 36-74; Emir Reitano, Manuel A. Fresco, antecedentes del gremialismo peronista (Buenos Aires: CEAL, 1992).

6 Una síntesis de ese cambio puede verse en Mirta Lobato y Juan Suriano, "Introducción. Trabajo, cuestión social", 9-53. Allí también hay estudios de casos que analizan las políticas laborales durante el período de entreguerras en las provincias de Córdoba, Mendoza, Santa Fe y Tucumán, y referencias a otros casos. 
las capitales de cada jurisdicción, por lo cual aún desconocemos cómo se desarrollaron las nuevas iniciativas legislativas al interior de los espacios provinciales.

En este artículo se pretende continuar dando cuenta de la segunda cuestión señalada y que hemos comenzado a abordar sobre todo para la década de $1930^{7}$. Es necesario analizar cómo se relacionó el DPT con las comunidades del interior bonaerense para saber si su accionar las impactó . Con el objetivo de conocer cómo fue la implementación inicial de las primeras políticas laborales en ese contexto apelaremos a un estudio de caso para analizar su importancia en el centro de la provincia. El partido de Tandil permite trabajar la problemática porque fue entre 1910 y 1940 que pasó de ser un pueblo que satisfacía las demandas del binterland rural circundante ${ }^{8}$, a una de las ciudades intermedias más relevantes del centro bonaerense? Reducir la escala a la perspectiva local es relevante para estudiar la acción estatal en la regulación de las relaciones laborales por dos razones:

a) Para complementar la perspectiva tradicional construida a partir de lo que aconteció en la capital provincial (La Plata). Siendo contextos muy distintos (a nivel demográfico, cultural, etc.), el interior bonaerense presentaba problemáticas obreras diferentes respecto a las que surgían en grandes ciudades del país como Buenos Aires, La Plata o Rosario.

7 Luciano Barandiarán,. "Estado y trabajo. Las políticas públicas y los trabajadores rurales pampeanos en los inicios del Estado "interventor" (1925-1950)" (tesis de Doctorado en Historia, UNCPBA, 2008), 190-240.

8 Hacia 1880 comenzó en Tandil una etapa de crecimiento ligada a la producción rural, principal actividad económica de la ciudad desde su creación en 1823. Ello también se debió a que era el principal centro de abastecimiento de bienes y servicios de gran parte del sudeste provincial, abarcando un área de gran influencia que comprendía la zona rural de partidos cercanos como Ayacucho o Benito Juárez. Eduardo Miguez, "Política, participación, poder. Los inmigrantes en las tierras nuevas de la provincia de Buenos Aires en la segunda mitad del siglo XIX", Estudios Migratorios Latinoamericanos No. $6 / 7$ (1987): 351.

$9 \quad$ El partido de Tandil se ubica al sudeste de la provincia de Buenos Aires, la más importante del país por la cantidad de población y su desarrollo económico, vinculado centralmente a la producción agropecuaria. La ciudad cabecera del partido es la ciudad homónima en la que habitan cerca de 120.00 habitantes. No existen más ciudades en el partido, siendo María Ignacia Vela la localidad rural con más población (alrededor de dos mil habitantes). En Argentina se califica a una ciudad como "intermedia" cuando tiene entre 50.000 y 500.000 habitantes. Entre las décadas de 1910 y 1940 el tejido urbano de la ciudad de Tandil pasó de ser rururbano (uso del suelo con menor densidad de edificación para viviendas, presencia de lotes sin uso específico y pequeños establecimientos de granja con actividades agropecuarias) a urbano (uso del suelo predominante de tipo residencial, con usos comercial y servicios urbanos). Guillermo Velázquez, Diana Lan y Graciela Nogar, Tandil a fin del milenio. Una perspectiva geográfica (Tandil: CIG-FCH UNCPBA, 1998), 21. 
b) Para conocer el impacto social real de las políticas laborales. Más allá de la mera sanción legislativa, las diferencias entre los supuestos teóricos contenidos en las normas y su aplicación generaron numerosos conflictos en los que las autoridades debían intermediar a nivel local, al menos en el interior de la provincia.

Para ello se analizarán las formas a través de las cuales las normas laborales impulsadas por el Estado provincial y sus funcionarios se aplicaron; y cómo fueron acogidas en la localidad. Nos vamos a centrar en el estudio de la aplicación en Tandil de la primera ley laboral argentina, la Ley de Descanso Dominical de 1905 (número 4.661). Se trató de una problemática del bienestar que se impulsó desde el Estado para mejorar las condiciones de vida de la población, pretendiendo de esa forma dar respuestas a demandas que emergían a raíz de la "cuestión social" a inicios del siglo $\mathrm{XX}$, demandas con fuerte arraigo en el movimiento obrero como lo era la del descanso dominical. La implementación de la norma genera conflictos, y fue lo que sucedió a nivel local con aquella. Por ende, explicar su impulso por parte del DPT implica explorar los intersticios a través de los cuales se pretendió respetarla y a su vez burlarla.

El análisis se circunscribe al período 1917-1930, primera etapa de funcionamiento de aquel organismo, menos conocida en relación a la que se inició en 1930. Coincidió con la gestión de los gobiernos radicales a nivel nacional y provincial (1916-1930). Los documentos centrales utilizados han sido medios de prensa locales: el diario de tendencia radical Nueva Era (NE) y en menor medida el periódico El Eco de Tandil (EEDT), que se editaba los días jueves y domingos y cuya orientación ideológica en estos años fue más independiente respecto a los partidos políticos existentes ${ }^{10}$. Ello implica que mientras que en el segundo caso no se observan grandes variaciones respecto a la mirada sobre la intervención estatal en el mundo del trabajo, en la primera fuente el análisis del cumplimiento o no de la norma se vincula con la afiliación política de su director, el escribano José

10 Las publicaciones del DPT del período hacen referencias muy limitadas sobre el accionar de sus funcionarios en el interior provincial. Por otro lado, a nivel local no se han conservado las actas policiales de los procedimientos efectuados en este período, por lo cual utilizamos la prensa para observar la injerencia de los inspectores del organismo laboral provincial en el plano local. 
Antonio Cabral, más cercana al yrigoyenismo que al radicalismo antipersonalista. Por esa razón, durante la presidencia de Alvear (1922-1928) puede observarse una mirada más crítica de NE hacia el accionar del DPT ${ }^{11}$.

En principio, se describe el surgimiento del DPT en el marco de la creación de agencias nacionales y provinciales vinculadas con la problemática obrera. Luego se explica el marco legal bajo análisis, concretamente la Ley de Descanso Dominical de 1905 y su par provincial. Posteriormente se estudian las formas en que la ley se manifestó y se implementó, abordando su aplicación en el espacio rural y urbano, comparando diferencias y semejanzas. Finalmente, se esbozarán las primeras conclusiones en torno a la importancia que pudo tener aquella ley en el caso bajo estudio.

\section{La “CUESTIÓN SOCIAL”, EL SURgimiento DE LOS ORgaNismos LABO- RALES Y EL DPT}

Los Departamentos de Trabajo emergieron a inicios del siglo XX al destacarse entre otros problemas propios de la "cuestión social" el aumento de la protesta obrera, protesta que emergía con fuerza ya desde las últimas décadas del siglo anterior. Desde el Estado nacional se generaron políticas destinadas a regular las relaciones laborales. La creación en 1907 del DNT tuvo su origen en el proyecto de Código de Trabajo de Joaquín V. González de $1904^{12}$, proyecto no sancionado pero que señaló el interés estatal por resolver los problemas socio-laborales ${ }^{13}$. En las décadas siguientes surgieron los organismos laborales provinciales, pues el régimen constitucional federal del país y la falta de definiciones sobre la naturaleza del vínculo laboral determinaron que fueran las provincias quienes reglamentaran y aplicaran la legislación laboral nacional ${ }^{14}$. Por ello hasta mediados de la década de 1940 el DNT solo tuvo jurisdicción sobre Capital Federal y los

11 Para entender mejor la división radical de la década de 1920 remitimos al clásico libro de David Rock, El radicalismo argentino, 1890-1930 (Buenos Aires: Amorrortu, 2001).

12 Juan Suriano, "El Estado argentino frente a los trabajadores urbanos: política social y represión, 1880-1916”, Anuario de la Escuela de Historia, No. 14 (1989): 109-110.

20213 Eduardo Zimmermann, Los liberales reformistas, 11-15.

14 Mariana Garzón Rogé, "Las relaciones laborales en la mira del Estado provincial de Mendoza", en La sociedad del trabajo. Las instituciones laborales en la Argentina (1900-1955), comp. Mirta Lobato y Juan Suriano (Buenos Aires: Edhasa, 2013), 131-136. 
Territorios Nacionales, aunque durante los años 30 el DNT y los departamentos provinciales participaron activamente en la regulación estatal de las relaciones laborales ${ }^{15}$.

El DPT bonaerense fue creado en diciembre de 1916 a raíz de un proyecto presentado por los diputados socialistas Adolfo Dickmann y Jacinto Oddone en 1914. Al existir leyes laborales nacionales, creían necesario que la provincia tuviera un organismo propio encargado de los asuntos laborales como lo era el DNT a nivel nacional. Propusieron transformar a la "Oficina de Estadística" en la "Oficina de Estadística y del Trabajo", llamada desde enero de 1917 "Dirección General de Estadística y Departamento de Trabajo"16.

Durante la gobernación del radical José Camilo Crotto (1918-1921) ${ }^{17}$, el director del DPT Aditardo Figueroa Ozzán intervino en los conflictos agrarios producidos desde 1918, especialmente en los sucesos de Tres Arroyos de diciembre de $1919^{18}$. El nivel de conflictividad obrera se mantuvo en

15 Miguel Murmis y Juan Carlos Portantiero, Estudios sobre los orígenes del peronismo (Buenos Aires: Siglo XXI Editores, 2004 [1971]), 136-149; Hugo Del Campo, Sindicalismo y peronismo. Los comienzos de un vínculo perdurable (Buenos Aires: Siglo XXI Editores, 2005 [1983]; Ricardo Gaudio y Jorge Pilone, "El desarrollo de la negociación colectiva durante la etapa de modernización industrial en la Argentina. 1935-1943”, Desarrollo Económico Vol. 23 No. 90 (1983): 255-286; Ricardo Gaudio y Jorge Pilone, "Estado y relaciones laborales en el período previo al surgimiento del peronismo, 1935-1943”, Desarrollo Económico Vol. 24 No. 94 (1984): 235-273; Roberto Korzeniewicz, "Las vísperas del peronismo. Los conflictos laborales entre 1930 y 1943”, Desarrollo Económico Vol.33 No. 131 (1993): 323.

16 María Angélica Corva y Horacio García Bossio, "El derecho laboral antes de Perón. Origen del Departamento de Trabajo de la Provincia de Buenos Aires", en Actas de las Primeras Jornadas de Historia Argentina. Hacia el Bicentenario de Mayo (La Plata: Universidad Católica Argentina, 2003).

17 Crotto fue uno de los fundadores de la Unión Cívica Radical en 1891. Cercano a Hipólito Yrigoyen, en 1909 fue presidente del Comité Nacional de la UCR. En 1912 fue electo senador nacional representando a la ciudad de Buenos Aires, cargo que abandonó en 1918 tras ser elegido gobernador de la provincia de Buenos Aires. Debido a un enfrentamiento personal con el presidente Yrigoyen, renunció al cargo en 1921, completando el período su vicegobernador Luis Monteverde. Tras ese acontecimiento Crotto fue un oponente a Yrigoyen al interior del radicalismo.

18 Entre 1917 y 1921 Yrigoyen debió enfrentar una serie de importantes huelgas en la ciudad y el campo vinculadas al impacto del fin de la Primera Guerra Mundial sobre las condiciones de trabajo. En algunas de ellas, en especial las vinculadas al transporte marítimo y ferroviario, el Gobierno nacional medió a favor de los obreros. Pero en otros conflictos, la respuesta estatal hacia ellos fue la represión, en especial los obreros metalúrgicos involucrados en "La semana trágica" (1919); los obreros del sudeste bonaerense que trabajaban en la cosecha del trigo (1919); y los obreros rurales que trabajaban en la esquila en la Patagonia (1921). David Rock, El radicalismo argentino, 155-221; G. Cuadrado Hernández, "La rebelión de los braceros", Todo es historia No. 18 (1982): 88. 
alza hasta aproximadamente 1922. A partir de ese año, el gobernador José Luis Cantilo (1922-1926), en un clima político y social más desmovilizado que el que enfrentaron sus antecesores, impulsó modificaciones a favor de los trabajadores. Opinaba que el DPT debía controlar la política laboral hasta que la provincia no tuviera Ministerio de Trabajo, sosteniendo una política de "unión de clases" entre patrones y obreros. Bajo su gobierno se reestructuró el organismo, creando delegaciones regionales en Avellaneda, Bahía Blanca, Junín y Zárate; y separándolo de la Dirección General de Estadística. Desde entonces, el DPT dependería del Ministerio de Gobierno ${ }^{19}$.

Como la ley orgánica que reglamentó su funcionamiento se promulgó durante la gobernación de Manuel Fresco en $1937^{20}$, sus iniciativas encontraron en la década de 1920 diversas limitaciones. Al igual que los organismos de otras provincias, la escasez de personal y la falta de presupuesto conspiraron contra su eficiencia, así como la carencia de capacidad ejecutiva para imponer sus decisiones ${ }^{21}$. Pero si bien en Buenos Aires, como ya se señaló, la intervención estatal en el mundo del trabajo se intensificó durante el gobierno de Fresco (1936-1940)22, ya los gobiernos conservadores anteriores (1930-1936) y los gobiernos radicales de la década de 1920 habían señalado la obligación del Estado provincial de intervenir en el plano de las relaciones laborales ${ }^{23}$.

Durante la década de 1920 el DPT debió vigilar el cumplimiento en la provincia de varias leyes laborales. Las más importantes fueron: la de Descanso Dominical (Ley 4.661 de 1905); las que reglamentaron el trabajo

19 Luciano Barandiarán, "Estado y trabajo, 203.

20 María Angélica Corva y Horacio García Bossio, El derecho laboral antes, 13.

21 Adrián Ascolani, "Orígenes de la legislación laboral agraria en Argentina. Vinculaciones con la política y la economía, 1900-1930”, Anuario de la Escuela de Historia No. 16 (1993), 145-161; Luciano Barandiarán, "Estado y trabajo, 215; María José Ortiz Bergia, "El intervencionismo estatal en el espacio provincial. Construcción de políticas laborales en Córdoba, 1930-1943”, Población y Sociedad No. 16 (2009): 172.

20422 Bibliografía ya mencionada en la nota al pie número 5.

23 Luciano Barandiarán, "Estado y trabajo, 201. Al igual que otras dependencias laborales provinciales y el DNT, el DPT presentaba paralelamente similares falencias y limitaciones, pero también una intervención prolífica en la medida de sus posibilidades y sus proyecciones. Remitimos para tal comparación a Mirta Lobato y Juan Suriano, "Introducción. Trabajo, cuestión social, 9-53. 
de mujeres y menores (Ley 5.291 de 1907 y Ley 11.317 de 1924); la Ley sobre Indemnización por Accidentes de Trabajo (Ley 9.688 de 1915); la Ley sobre Trabajo a Domicilio (Ley 10.505 de 1918); las normas que establecieron las modalidades para el pago de salarios en moneda (Ley 11.278 de 1923 y ley 11.337 de 1926); la Ley que reglamentó el trabajo nocturno (Ley 11.338 de 1926); y la que estableció la jornada laboral de ocho horas (Ley 11.544 de 1929).

A inicios de 1944 el DPT fue absorbido por el gobierno nacional, convirtiéndose en "delegación regional” de la Secretaría de Trabajo y Previsión ${ }^{24}$. Comenzó así una nueva etapa en la relación entre Estado y mundo del trabajo al centralizarse la política laboral desde el gobierno federal. Aunque existió por casi tres décadas, pocos trabajos historiográficos dieron cuenta del DPT y sus funcionarios antes de $1930^{25}$.

\section{La Ley de Descanso Dominical}

Se ha señalado que hasta el advenimiento del peronismo en la década de 1940 el sistema de relaciones laborales en Argentina era precario. Los avances legislativos desde 1904 habrían sido modestos; al respecto se ha hecho referencia a los vacíos en tres normas laborales sancionadas entre 1905 y 1929, entre ellas la de Ley de Descanso Dominical de 1905, que habría tenido vigencia solo en Capital Federal, estando sujetas sus disposiciones a variadas restricciones ${ }^{26}$. Sin embargo, esa ley tuvo vigencia muy temprano en otros espacios, incluida la provincia de Buenos Aires ${ }^{27}$.

24 Daniel Campione, Orígenes estatales del peronismo, 110.

25 Las excepciones son: G. Cuadrado Hernández, La rebelión de los braceros, 82-91p; Adrián Ascolani, El sindicalismo rural argentino (Buenos Aires: Universidad Nacional de Quilmes, 2009), 17-27.

26 Juan Carlos Torre, “Transformaciones de la sociedad argentina”, en Argentina 1910-2010. Balance del siglo, eds. Roberto Russell (Buenos Aires: Taurus, 2010), 194. Las otras dos leyes a las que hace referencia es a la Ley de Accidentes de Trabajo de 1915, que habría dejado cabos sueltos en cuanto a la interpretación sobre sus beneficios; y la Ley sobre Jornada Legal de Trabajo de ocho horas de 1929, pues en la ciudad de Buenos Aires era una práctica desde hacía diez años.

27 Lo mismo parece haber acontecido en Mendoza, donde los comerciantes querían que sus empleados pudieran trabajar los domingos, dando la pauta de que cumplir con la disposición era más la regla que la excepción: Mariana Garzón Rogé, "Las relaciones laborales en la mira, 134. También en Tucumán el DPT provincial controló el acatamiento de la ley reglamentada en la provincia en 1907: Alejandra Landaburu, "Los industriales y el Departamento Provincial del Trabajo ante el conflicto obrero de 1919 en Tucumán", en La sociedad del trabajo. Las instituciones laborales en la Argentina (1900- 
La ley que estableció el descanso semanal en domingo en Capital Federal fue la primera norma laboral sancionada en Argentina ${ }^{28}$. Surgió por iniciativa del doctor. Alfredo L. Palacios, primer diputado socialista de América a raíz del mencionado proyecto de Código del Trabajo de 1904. Como el proyecto fue cuestionado Palacios propuso que se lo tratase en forma parcial rescatando el descanso dominical. El proyecto se presentó en la Cámara de Diputados de la Nación el 26 de septiembre de 1904. Durante su consideración el diputado Argerich presentó otro proyecto y fue sobre este último que se desarrollaron las discusiones (la diferencia se presentaba si el día de descanso dominical debía ser el domingo o podía ser otro día). Las reformas introducidas eliminaron sus diferencias con el proyecto del Poder Ejecutivo ${ }^{29}$. Por ende, fue este último el que se sancionó con leves modificaciones por la Cámara de Senadores el 29 de agosto de 1905.

El texto de la Ley 4.661 se publicó el 9 de septiembre de 1905. Prohibía en domingo el trabajo material por cuenta ajena y el que se efectuara por cuenta propia en las fábricas, talleres, casas de comercio y demás sitios de trabajo en Capital Federal. Se exceptuaban los trabajos que no pudieran interrumpirse por las necesidades que satisfacían, por motivos técnicos o por razones que determinaran perjuicio de interés público; los trabajos de reparación o limpieza indispensables para no interrumpir las faenas de la semana en establecimientos industriales; los trabajos que fueran perentorios por inminencia de daño, por accidentes naturales o por circunstancias transitorias que fuera menester aprovechar. En esos casos los reglamentos posteriores de la ley determinarían el descanso semanal de los que tuvieran

1955), comp. Mirta Lobato y Juan Suriano (Buenos Aires: Edhasa, 2013), 91. En Córdoba entre las normativas que reglamentaban las relaciones laborales también se menciona el descanso dominical: María José Ortiz Bergia, "El tratamiento estatal de la “cuestión obrera” en Córdoba, 1930-1943”, en La sociedad del trabajo. Las instituciones laborales en la Argentina (1900-1955), comp. Mirta Lobato y Juan Suriano (Buenos Aires: Edhasa, 2013), 185.

28 Los antecedentes han sido analizados por Marcela Aspell, "La realidad social y la regulación jurídica del descanso dominical, los días festivos, los horarios de trabajo", Cuadernos de Historia No. 12 (2002): 67-84. La autora sostiene que debido a la influencia de la Iglesia Católica, en la primera mitad del siglo XIX el descanso dominical era una práctica que recién se cuestionó en la segunda mitad del siglo XIX al predominar elementos propios del discurso liberal que concibieron al descanso obrero como sinónimo de ocio y vagancia. Por ende, a inicios del siglo XX el descanso dominical comenzó a ser una demanda creciente del mundo obrero, y una práctica criticada por numerosos patrones.

29 Honorable Cámara de Diputados de la Nación, "Descanso Dominical", Diario de Sesiones de la Cámara de Diputados, Buenos Aires, 26, 28 y 30 de septiembre, 1904, 546-628. 
que trabajar en domingo. La obligación del descanso hebdomadario no tenía excepciones en cuanto a mujeres y menores de 16 años. La ley no se aplicaría al servicio doméstico. Los días domingo permanecerían cerradas las casas de expendio de bebidas. Las infracciones a la ley se imputarían a los patrones salvo prueba en contrario; serían penados la primera vez con cien pesos, y en las reincidencias con doble multa o quince días de $\operatorname{arresto}^{30}$.

En la provincia de Buenos Aires la Ley de Descanso Dominical se sancionó en enero de 1908 bajo el gobierno de Ignacio D. Irigoyen. La Ley provincial 3.098 prohibió en los centros urbanos y casas de comercio de toda la provincia el trabajo material por cuenta ajena y el que se efectuara por cuenta propia el domingo. Se exceptuaba de la prohibición los trabajos que no pudieran ser interrumpidos sin perjuicio, al igual que lo hacía la norma nacional. Al igual que a nivel nacional, las excepciones no se aplicarían a mujeres ni a menores de 16 años, ni la ley se aplicaría al servicio doméstico; las infracciones a la misma se imputarían a los patrones, salvo prueba en contrario, siendo penadas la primera vez con 100 pesos de multa y si reincidían con 500 pesos o dos meses de arresto. Dos meses después se sancionó el decreto reglamentario de la ley, no estableciendo grandes diferencias en relación a la norma, pero señalando que si una industria o comercio tenía la necesidad de hacer trabajar el domingo debería solicitar permiso a la Policía. A nivel provincial, esa agencia sería la encargada del cumplimiento de la Ley 3.098.

Pronto se presentaron otros decretos modificando la aplicación del decreto reglamentario original. Así, por ejemplo, el 27 de abril otro decreto establecía que debido a quejas recibidas sobre la clausura de casas de comercio que producían perjuicios en la zona rural, el Poder Ejecutivo provincial había establecido que las casas de comercio podrían permanecer abiertas hasta el mediodía. En los siguientes años diferentes gremios y asociaciones

30 Ministerio de Justicia e Instrucción Pública, "Ley de descanso dominical”, Boletín Oficial de la República Argentina, Buenos Aires, 9 de septiembre, 1905, 1. En 1932 se alteró el régimen del descanso semanal al introducir la Ley 11.640 el "sábado inglés", estableciendo la prohibición de trabajar a partir de las 13 horas del día sábado. Ambas leyes fueron derogadas por la Ley 18.204 en mayo de 1969. 
intentaron modificar la ley. Así, por ejemplo, el 24 de julio 1917 los comerciantes de cigarrería y agencias de lotería de Dolores (ciudad ubicada al este de la provincia) solicitaron despachar los domingos hasta mediodía por la competencia que sufrían frente a vendedores ambulantes, almacenes y confiterías, pero no se dio lugar a lo solicitado ${ }^{31}$.

La Policía vigiló el cumplimiento del descanso dominical desde la sanción de la ley en 1908 hasta diciembre de 1917. A partir de esa fecha en lugar de la Policía en fuentes oficiales como las leyes provinciales o el Registro Oficial, fue la Dirección del DPT la que comenzó a sugerir al Gobierno aceptar o no las solicitudes presentadas por distintas asociaciones para modificar la mencionada ley. A pesar de la variación de la autoridad de aplicación, dadas las limitaciones de la nueva agencia laboral en especial a lo atinente a su cantidad de inspectores, la Policía provincial continuaría siendo un actor relevante en la aplicación de la Ley de Descanso Dominical, al tener que auxiliar al DPT en sus procedimientos.

\section{La aplicación de la Ley de Descanso Dominical en Tandil}

El arribo del ferrocarril a Tandil en 1883 posibilitó la mayor integración a los mercados nacionales e internacionales de la producción local, vinculada a la agricultura, la ganadería y la minería. También impulsó entre aquel año y 1930 la creación en la zona rural del partido de estaciones ferroviarias (Azucena, De la Canal, Fultón, Gardey, Iraola, La Pastora, Vela). Así, además de la población que iba adquiriendo características urbanas en la ciudad de Tandil y de la población rural dispersa en los establecimientos rurales, se sumó la población rural asentada en aquellas estaciones que crearon pequeñas localidades como Gardey o Vela ${ }^{32}$.

31 Toda la información vinculada a la Ley provincial 3.098 y sus sucesivas reglamentaciones ha sido extraída de: Provincia de Buenos Aires, eds. Ministerio de Gobierno de la Provincia de Buenos Aires, Legislación bonaerense (La Plata: 2010), http://www.gob.gba.gov.ar/intranet/digesto/PDF/ ley3098.pdf (25 de marzo de 2015).

32 Valeria Palavecino, "Surgimiento de poblados al sur de la provincia de Buenos Aires. El ferrocarril y las poblaciones rurales en el partido de Tandil (1880-1955)". En Segundas Jornadas Nacionales de Historia Social (Córdoba: Centro de Estudios Históricos Prof. Carlos Segreti, 2009), http:// cehsegreti.org.ar/historia-social-2/mesas\%20ponencias/MESA $\% 2012 /$ Ponencia $\% 20$ Valeria $\% 20$ Palavecino.pdf (4 de agosto de 2016). 
Las actividades rurales y mineras continuaron siendo las principales actividades generadoras de empleo hasta 1930. Paralelamente aparecieron numerosos talleres -herrerías, carpinterías, talabarterías, etc.- e industrias, como fábricas de fideos, licores y chacinados, jabonerías y derivados de la leche, molinos harineros y hornos de ladrillos. A raíz de esas actividades entre 1860 y 1930 Tandil experimentó un importante crecimiento económico.

Fueron los gremios vinculados a actividades secundarias y terciarias localizados de manera predominante en el medio urbano los que más tempranamente surgieron. Organizados en los primeros años del siglo XX, los de los panaderos, sastres y costureras y tipógrafos se formaron como sociedades de resistencia. Ello implicó el surgimiento de un movimiento obrero caracterizado por la presencia de ideas socialistas (sobre todo entre los trabajadores ferroviarios); y la predominancia de ideas anarquistas, en especial entre los picapedreros. Estos residían en las canteras de granito, apartados de la ciudad. En octubre de 1906 crearon la Sociedad Unión Obrera de las Canteras. En 1908 protagonizaron la "gran huelga", que duró once meses, obteniendo el aumento de salarios y la reducción de la jornada laboral durante el verano. Los enfrentamientos de las organizaciones obreras con los patrones y con las autoridades policiales continuarían siendo numerosos en los años siguientes.

A inicios de la década de 1920 el movimiento obrero tandilense estaba representado por algunos gremios autónomos, la Confraternidad Ferroviaria (los gremios ferroviarios - La Fraternidad y la Unión Ferroviaria- contaban con 436 afiliados) y la Federación Obrera Local (FOL) de tendencia anarquista, integrada por tres gremios y sumando en total 1.500 afiliados, si bien muchos se hallaban fuera de la región. Junto a los panaderos y los trabajadores del campo su núcleo central eran los canteristas. Pero entre 1920 y 1930 comenzó a declinar su importancia, al igual que lo hizo la industria del granito ${ }^{33}$. Por su parte, en relación a los trabajadores del cam-

33 El reemplazo del adoquín por el hormigón en los planes de obras públicas; las conquistas obtenidas por los obreros picapedreros que le restaron rentabilidad a las empresas mineras; y los enfrentamientos entre anarquistas y sindicalistas en el plano gremial fueron las principales causas de la declinación de la industria minera local. Hugo Nario, Los picapedreros (Tandil: Ediciones del Manantial, 1997), 6. 
po que integraban la FOL, en 1920 se había creado en Balcarce la Unión Obrera de las Colonias Paperas, a instancias de la Unión Obrera de las Canteras de Tandil. Se trataba de miembros de este último gremio que al paralizarse las tareas en las canteras se iban a cosechar papa, por eso sus secciones se localizaron en lugares donde también había canteras (Tandil, Gardey, La Morocha, San Luis, Punta del Diablo, La Gruta, Rincón y Napaleofú) ${ }^{34}$. El mismo origen tuvo la Unión de Trabajadores Agrícolas, que en Tandil logró persistir hasta $1923^{35}$, más allá del conflictivo período 1918-1922. Durante esos cuatro años, el movimiento obrero realizó numerosas huelgas en Tandil, al igual que aconteció a nivel nacional.

La gran mayoría de los trabajadores rurales de Tandil no se agremiaron; hacia 1914 residían allí 34.061 habitantes de los cuales el 54 \% (18.391 personas) lo hacían en la campaña, tendencia que se revertiría en los años siguientes. Para 1947, el 57 \% de los habitantes del partido residían en la ciudad. Tendencia visible a nivel nacional y local, mientras que el porcentaje de la población rural disminuyó en Argentina del 47,3 \% en 1914 al $37,5 \%$ en 1947, en Tandil el cambio implicó la disminución del 54\% al $38,95 \%$; si bien se observa un aumento absoluto de la población rural entre ambos años (22.047 personas en 1947), se produjo una fuerte disminución desde el punto de vista relativo al incrementarse notoriamente la población urbana (34.556 habitantes el mismo año).

Ese proceso se relacionó con los efectos de la crisis de 1930. Además de la minería, también declinó el trabajo en las actividades agrícolas, pues los propietarios de tierra se volcaron hacia la ganadería, que requería menor cantidad de mano de obra. Los desocupados de la piedra y de la agricultura tenían escasas alternativas ocupacionales en Tandil, pues la industria metalúrgica recién se estaba iniciando, siendo limitados sus requerimientos de mano de obra. Por esa razón muchas familias rurales debieron emigrar ${ }^{36}$.

34 Eduardo Sartelli, "De estrella a estrella... De sol a sol... Huelgas de braceros en Buenos Aires, 19181922", en Conflictos obreros rurales pampeanos (1900-1937), tomo I, comp. Waldo Ansaldi (Buenos Aires: CEAL, 1993), 115-116.

35 "Movimiento Obrero", Nueva Era, Tandil, 20 de junio de 1923, 4.

36 Guillermo Velázquez, Población y empleo en el partido de Tandil (1914-1985) (Tandil: Municipalidad de Tandil-UNCPBA, 1989), 2. Los datos estadísticos permiten observar el impacto de la crisis de 
Fue entre 1914 y 1940 que se produjo el estancamiento de la economía rural y el despegue industrial urbano, un marco en el cual Tandil pasó de ser un pueblo a una ciudad intermedia. Por eso aún podía leerse en la prensa local en las décadas de 1920 y 1930 críticas a la persistencia de elementos propios de la ruralidad que no se ajustaban a la visión de una sociedad moderna que se pretendía instalar desde la prensa ${ }^{37}$.

\subsection{La aplicación de la Ley de Descanso Dominical en el campo tandilense}

En mayo de 1925 los obreros rurales Julio Castro y Albino Garrido que paraban en la fonda "La Coruñesa" frente a la estación de trenes se presentaron a la redacción del diario NE. Habían trabajado en la chacra de don Martin Lavayen, próxima a la estación Fultón, ganando $\$ 4,50 \mathrm{~m} / \mathrm{n}$ por día. Pero no habían podido cobrar sus jornales a pesar de las gestiones realizadas siendo uno de ellos amenazado de muerte. Castro reclamaba el pago de 44 días de trabajo y Garrido de 12 días y medio. El diario señalaba que estas quejas eran frecuentes, y los trabajadores no hallaban justicia de parte de los patrones ${ }^{38}$. Quejas como esas continuarían apareciendo en la prensa al menos hasta inicios de la década de 1940. Recién allí se consolidaría un derecho laboral que también abarcaría a los trabajadores rurales; pero hasta ese momento la mayor parte de los mismos no estuvieron cu-

1930 sobre el trabajo rural en Tandil. Hacia 1914 el personal ocupado en explotaciones agropecuarias eran 8.143 personas (considerando a los 876 directores de explotaciones agropecuarias, sus 4.026 familiares y las 3.241 personas ajenas a la familia que allí trabajaban). República Argentina, Tercer Censo Nacional 1914. Tomo V Explotaciones agropecuarias (Buenos Aires: Talleres Gráficos de L. J. Rosso y Cía, 1919), 575. La proporción del personal ocupado en actividades rurales hacia 1914 representaba el $40 \%$ de la población rural, y el $21 \%$ de la población total del partido de Tandil. Pero de acuerdo al Censo Agropecuario de 1937, la Población Económicamente Activa rural del partido eran 9.920 personas. Eso implicaba un $22 \%$ más que en 1914 cuando habían sido 8.143, pero era una merma comparado a los últimos años de la década de 1920, cuando se acercó a las 12.000 personas. Guillermo Velázquez, "La dinámica de la población tandilense: el marco histórico-geográfico”, en Tandil a fin de milenio: una perspectiva geográfica, comp. Guillermo Velázquez, Diana Lan y Graciela Nogar (Tandil: CIG/FCH/UNCPBA, 1998), 62.

37 Por ejemplo, las denuncias por animales muertos (bovinos y equinos) dejados en la vía pública; el corte de alambrados cuando afectaba el paso de un sujeto ("Un tema de interés. La facultad de cortar alambrados", Nueva Era, Tandil, 14 de abril de 1924, 1); o la persistencia de la costumbre de dejar el cuero del animal (bovino u ovino) a su dueño tras matarlo para usarlo como alimento ("Cuatrerismo", El Eco de Tandil, Tandil, 17 de septiembre de 1919, 2).

38 "Quejas del pueblo. Dos obreros que no pueden cobrar", Nueva Era, Tandil, 11 de mayo, 1925, 1. 
biertos por la incipiente legislación obrera que sí otorgó derechos a trabajadores urbanos desde los primeros años del siglo $\mathrm{XX}^{39}$.

A mediados de la década de 1920 el director del DPT Bernardo Aineseider señalaba que los trabajadores rurales se encontraban en un vacío legal. Solo se ocupaban de ellos las leyes sobre trabajo de mujeres y menores y la ley sobre pago de salarios en moneda nacional. Estaban excluidos de otras leyes como la de Descanso Dominical. La celebración de contratos de seguros sobre riesgos de trabajos entre patrones y compañías aseguradoras se efectuaba como simple contrato de seguro y sin fiscalización estatal ${ }^{40}$. En su opinión, la legislación argentina debía considerar que el trabajo del campo estaba expuesto a riesgos similares a los trabajos industriales. Existía tanto peligro en el engranaje de una máquina, como al sacarle el cuero a un vacuno muerto que tuviera carbunclo. Además, en las conferencias internacionales del trabajo que ya había realizado la Organización Internacional del Trabajo (OIT) habían surgido iniciativas para proteger a los trabajadores del campo que debía considerar el Congreso Nacional. Pero había temas que podía reglamentar el gobierno provincial, como el horario de trabajo; por eso se había impulsado el tratamiento en el período de sesiones extraordinarias de la Legislatura bonaerense la limitación de la jornada de los trabajadores del campo ${ }^{41}$.

39 La Ley nacional 9.688 de indemnización de accidentes del trabajo y enfermedades profesionales tal vez sea el mejor ejemplo; sancionada en 1915, la mayor de parte las tareas agrícolas fueron excluidas deliberadamente de la norma, pues adoptó un sistema de reparación de accidentes del trabajo propio de países industrializados, usando como modelo la Ley francesa de 1898. Solo los trabajadores rurales ocupados en el transporte o servicio de motores inanimados y en el transporte de carga y descarga estaban amparados. La idea subyacente era que los únicos accidentados del campo que debían protegerse eran los que se vinculaban al trabajo industrial. Benito Pérez, Los accidentes del trabajo en la agricultura (Buenos Aires: Editorial Sociedad Bibliográfica, 1943), 71. Para un análisis más detallado de los problemas que esta ley entrañó para los obreros rurales hasta al arribo del peronismo remitimos a Luciano Barandiarán, "Estado y trabajo, 248-264. Para su aplicación temprana en la ciudad de Buenos Aires, ver Ludmila Scheinkman, "Sujetos, instituciones y derechos en la implementación de la Ley de Accidentes del Trabajo en la ciudad de Buenos Aires (1915-1922)", Estudios Sociales. Año XXV No. 49 (2015): 125-154. También se ha analizado los cambios que sufrió la ley desde su sanción hasta la aparición del peronismo: Karina Ramacciotti, "¿Soldados del trabajo o ciudadanos? La Ley de Accidentes de Trabajo en la Argentina, 1915-1955”, en La sociedad del trabajo. Las instituciones laborales en la Argentina (1900-1955), comp. Mirta Lobato y Juan Suriano (Buenos Aires: Edhasa, 2013), 293-317.

40 Provincia de Buenos Aires, Departamento del Trabajo, 185.

41 Provincia de Buenos Aires, Departamento del Trabajo, 160-172. 
En el Congreso Internacional de Economía Social, realizado en Capital Federal en 1924 por iniciativa del Museo Social Argentino, el DPT ya había expuesto su interés por modificar la relación de la norma con los trabajadores del campo. En esa ocasión, sus funcionarios presentaron una ponencia en la que se proponía indemnizar los accidentes y las enfermedades profesionales ocurridos en el trabajo agrícola ${ }^{42}$; medida que solo podía tomar el Parlamento nacional. Recién se llevaría a cabo hacia 1940. Los cambios se vincularon al surgimiento y consolidación en esa década y en la anterior del derecho laboral. Y se profundizaron tras el golpe de Estado de 1943, al surgir normas específicas que beneficiaron a los obreros rurales (el estatuto del Peón -1944-, el estatuto de los tamberos-medieros -1946-, y la ley 13.020 para los trabajadores de cosecha -1947). Por ende, la aplicación de la Ley de Descanso Dominical en el ámbito rural fue más laxa que en el ámbito urbano, dado el contexto legislativo y jurídico señalado.

En el caso particular de Tandil, el accionar del DPT se manifestó mediante tres formas. En principio, a través de representantes directos que llegaban a la ciudad para vigilar la aplicación de las leyes laborales. La presencia más significativa fue la de los inspectores del organismo ${ }^{43}$. En segundo lugar, a través de la información que llegaba mediante la prensa, que actuaba como mediadora entre el organismo y la sociedad local, al exponer sus críticas, comentarios y sugerencias. Finalmente, a través de las reacciones que la injerencia del DPT en las relaciones laborales generaba tanto en forma individual como colectiva.

A diferencia de lo que acontecía en Capital Federal, en la provincia, la Ley de Descanso Dominical se aplicó en los centros urbanos y en las casas de comercio, muchas localizadas en el campo. Dichas "casas de comercio"

42 Provincia de Buenos Aires, Departamento del Trabajo, 175-181.

43 Durante la etapa inicial del DPT (1917-1922), los inspectores del organismo fueron tres, duplicándose su número en la gobernación de Cantilo a partir de 1923. Eran pocos considerando la extensión de la provincia, pero era un número importante comparado al cuerpo de inspectores de otros organismos laborales provinciales contemporáneos. Hemos observado su reclutamiento con base en vínculos familiares y políticos (radicales y en menor medida socialistas), con un promedio de edad de 18 y 28 años, siendo muchos de ellos estudiantes o egresados de la Universidad Nacional de La Plata. 
abarcaban un conjunto heterogéneo de establecimientos, pudiendo asumir la forma de la tradicional "pulpería" del siglo XIX, o la de medianos y grandes almacenes de ramos generales ubicados en localidades rurales. Cuando se hallaban en centros poblados, el responsable podía trabajar con uno o dos dependientes, además de la ayuda de su propia familia ${ }^{44}$. Como en esas localidades solía haber presencia policial, era en general en comercios más modestos ubicados en "esquinas" (el cruce de dos caminos), más cerca de la población rural dispersa que de la concentrada, donde la Ley de Descanso Dominical se burlaba abiertamente, y donde el consumo de alcohol generaba grescas que terminaban tras la intervención policial inmediata o posterior cuando el saldo de las peleas eran heridos o muertos, aumentando la violencia en esos espacios de sociabilidad. Al respecto debe recordarse que la ley también fue aprovechada para iniciar políticas contra el alcoholismo, intentando que las casas de expendio de bebidas etílicas no abrieran los días domingos ${ }^{45}$. De todos modos, la importancia de esos comercios en el ámbito rural bonaerense ayuda a entender por qué desde abril de 1908 se les permitió abrir sus puertas hasta el mediodía en lugar de permanecer cerrados todo el día.

Las primeras leyes laborales intentaron modificar costumbres, prácticas sociales y tradiciones, surgiendo nuevas ideas y acciones tendientes a adaptarse a las mismas o a modificarlas. El hábito de ir los domingos al almacén a beber con los paisanos era una de las tradiciones que la ley alcanzaba, y por lo cual era criticada en el ámbito rural. Si bien la Ley de Descanso Dominical no incluía a los trabajadores rurales de forma específica, si no había trabajo el domingo, en general ese día era el que aquellos junto a pequeños propietarios y arrendatarios concurrían a espacios de sociabilidad, como las carreras cuadreras o los bares. Eso era posible porque generalmente los funcionarios del DPT podían vigilar la aplicación de las normas solo en la ciudad; por su escaso número y también por las dificultades para llegar a esos lugares, al no contar con medios de transporte adecuados; ni

44 El mejor análisis sobre este tema en la zona rural de Tandil es sobre el almacén de ramos generales "El Progreso" de la familia Vulcano, ubicado en Gardey. Valeria Palavecino, "Comercio rural en la campaña bonaerense. Un estudio de caso: Casa de Comercio "El Progreso" de los Hnos. Vulcano (1922-1932)", Mundo Agrario Vol. 6 No. 12 (2006), 1-20.

45 Marcela Aspell, "La realidad social y la regulación, 84. 
con agentes policiales que pudieran ayudarlos, salvo en las localidades del partido donde hubiera destacamentos policiales. Por ende, era la Policía la que podía hacerlo en los lugares donde había una población rural asentada. Pero era más difícil en lugares donde la población rural se hallaba más dispersa. En síntesis, no solamente el DPT parecía no tener suficientes funcionarios, sino también la Policía, dada la cantidad de habitantes que residían en la campaña bonaerense en la década de 1920.

La Policía provincial debía prestar su cooperación al DPT y a sus delegaciones regionales en la vigilancia y comprobación de las infracciones a las leyes laborales ${ }^{46}$. Por eso en el ámbito rural era la Policía más que los funcionarios del DPT los que vigilaban la aplicación de la Ley de Descanso Dominical. Así, en septiembre de 1923 el comerciante Pompilio Yacaruso, que vivía en Estación Vela publicó una solicitada en la que denunciaba que el domingo a las 17 horas se había presentado en su negocio un individuo vestido de particular, el subcomisario de la localidad. Considerando que hacia 1921 vivían en Vela unas 3.783 personas ${ }^{47}$, el comerciante apelaba a una ironía para referirse al funcionario provincial, al dar a entender que no lo conocía. Aquel habría actuado en malos modos, "como está acostumbrado hacer con todos", y le ordenó que cerrara su establecimiento, informándole que si ignoraba lo que era la Ley de Descanso Dominical él se lo enseñaría. El comerciante explicaba que los domingos cerraba el almacén dejando abiertas las puertas de los despachos de frutas y confitería que vendía a sus clientes. Jamás se había relacionado con las autoridades policiales ni municipales y pagaba los impuestos. Se quejaba porque creía injusta la actitud policial, "que valiéndose de la autoridad que inviste pretende extorsionar a los comerciantes que honrada y honestamente se ganan la vida", dando a entender que el policía exigía coimas para que él no cerrara las puertas un domingo. Había muchas personas mal tratadas en el calabozo de la sub-comisaría y no se quejaban por el miedo que le tenían al funcionario, pero él no estaba dispuesto a tolerar el procedimiento injusto

46 Como se establecía por ejemplo en la Ley 11. 338 sobre trabajo nocturno de las panaderías. "Departamento del Trabajo. Ayer entró en vigor la ley que prohíbe el trabajo nocturno de los panaderos", Nueva Era, Tandil, 18 de abril, 1927, 2.

47 Valeria Palavecino, "Surgimiento de poblados al sur de la provincia, 16. 
con el que se lo pretendía extorsionar ${ }^{48}$. A pesar de ello, el comerciante no reconocía que infringía la ley, sino que criticaba la acción policial. Posiblemente los "modos" del funcionario no eran correctos, pero la norma establecía que debían cerrarse los comercios al mediodía, y el funcionario había concurrido a las 17 horas. Como ya se mencionó, incluso esos comerciantes gozaban de una ventaja añorada por muchos comerciantes del casco urbano de la ciudad de Tandil, como era poder abrir las puertas hasta mediodía.

\subsection{La aplicación de la Ley en el ámbito urbano}

En la ciudad sí actuaban los funcionarios del DPT. La infracción la constataba un inspector del organismo que debía estar en la ciudad un día domingo. Acompañado de policías, el inspector verificaba si el comercio cumplía con la ley, que solía infringirse en peluquerías, tiendas y despachos de bebidas. Labraba las actas y las elevaba a la Policía, que comunicaba a los infractores las multas establecidas. Tras recibirlas, había un plazo de 24 horas para apelar; algunos comerciantes invocaban la ilegalidad del procedimiento, aduciendo el incumplimiento de alguna cláusula legal, o procedimientos equívocos ${ }^{49}$.

Las multas por infringir la Ley de Descanso Dominical eran frecuentes, señal de su constante incumplimiento. En julio de 1922, a Francisco Molinari-que tenía despacho de bebidas- la policía le aplicó una multa de cien $_{\text {pesos }}{ }^{50}$. En mayo de 1928, por pedido de la Sociedad Empleados de Comercio (SEC), que solo tenía representatividad en el casco urbano, llegaron a la ciudad dos inspectores del DPT para vigilar el cumplimiento de la ley. Constatadas algunas infracciones, se procedió al levantamiento de las actas, que luego se elevaron a la comisaría local para aplicar las penali-

48 "Solicitada", Nueva Era, Tandil, 11 de septiembre, 1923, 2.

49 "Descanso dominical. Varios comercios multados", Nueva Era, Tandil, 3 de enero, 1923, 1; "Departamento del Trabajo de la Provincia. Los comerciantes multados", Nueva Era, Tandil, 12 de enero, 1923, 3. La policía continuaría teniendo importancia en estos procedimientos hasta 1937, cuando la ley orgánica del DPT le dio poder de policía para imponer multas al propio organismo.

50 "Multa a patrones que no cumplen la ley de descanso dominical", Nueva Era, Tandil, 3 de julio, 1922, 2. 
dades $^{51}$. Lo mismo sucedió en junio del año siguiente, cuando se aplicaron multas a comerciantes tandilenses por infringir la Ley 3.098, en un caso 500 pesos por reincidencia ${ }^{52}$.

Ante esta y otras quejas similares, el gobierno provincial ya había designado mucho antes a un delegado local del DPT para vigilar el cumplimiento de la Ley de Descanso Dominical y sus decretos reglamentarios, denunciar faltas y aplicar multas, además de vigilar el cumplimiento de otras leyes laborales $^{53}$. De esa forma, el DPT se propuso iniciar una acción enérgica "sin exclusiones ni miramientos de ninguna especie" $" 54$. Entre abril de 1921 y 1922 el vecino José Fiscalini representó al DPT en Tandil. Lamentablemente se trató de un simple representante, es decir, no influyó demasiado en el cumplimiento de las normas en tanto debía acompañar a los inspectores del DPT que llegaban desde La Plata, pero fue un antecedente que siempre se consideró, al propiciarse la creación de una delegación del DPT en Tandil ${ }^{55}$.

A pesar de haber sido sancionada en 1908, el incumplimiento de la Ley 3.098 fue tema de debate cotidiano en la prensa tandilense durante toda la década de 1920. En diciembre de 1928, NE mencionaba que la rebeldía para hacerla cumplir se podía observar en todos los pueblos debido a la indolencia oficial; eso se debía a que los encargados de hacer cumplir las disposiciones no sabían cómo hacerlo. En ocasiones el Poder Ejecutivo provincial se decidía a imponer la ley, como pasaba por esos días, al recibir la policía local una nota del Ministerio de Gobierno exigiendo su incumplimiento. Para NE, la acción de la Policía no debía reducirse a dos o tres domingos, sino persistir hasta que se acatara totalmente la disposi-

51 "Centro Empleados de Comercio. Visita de Inspección”, Nueva Era, Tandil, 28 de mayo, 1928, 3.

52 "Departamento del Trabajo. Aplicación de multas a comerciantes de Tandil por infringir la ley de descanso dominical”, Nueva Era, Tandil, 25 de junio, 1929, 1.

53 "El descanso dominical. Decretos reglamentarios", Nueva Era, 12 de abril, 1921, 1.

54 "Descanso dominical", El Eco de Tandil, Tandil, 28 de abril, 1921, 1.

55 En agosto de 1930 por ejemplo, la SEC se dirigió al diputado provincial Miguel Antonena para que se creara en Tandil una delegación de aquel organismo; o para que presentara un proyecto de ley con ese fin. Así se vigilaría el cumplimiento de las leyes que favorecían a los obreros "directamente beneficiados con la legislación de carácter social dictada por el parlamento nacional": "Se propicia la creación en esta ciudad de una delegación del Departamento del Trabajo de la Provincia", Nueva Era, Tandil, 12 de agosto, 1930, 3. 
ción oficial ${ }^{56}$. En los días siguientes el DPT aplicó numerosas multas por no cumplir con la ley en todo el territorio provincial, especialmente en los partidos de San Fernando, Las Conchas -actual Tigre-, Bahía Blanca, Avellaneda, Magdalena, Pergamino y Pehuajó. En Tandil se multó a un patrón con quinientos pesos por reincidir; y a otros 21 empresarios con cien pesos cada uno ${ }^{57}$.

Poco después, en junio de 1929, se volvía a insistir que en la provincia se infringía la ley. Los contraventores eran intransigentes a pesar de las sanciones que muchos ya habían recibido, y a pesar de las visitas más frecuentes de los inspectores del DPT al interior. Pero para la prensa los procedimientos implementados por esos funcionarios en ocasiones se apartaban de las leyes, pues había una parcialidad manifiesta contraria al principio de justicia. Dicha parcialidad se debía a intereses creados por la política, siendo multados aquellos que no contaban con influencias partidarias. Esas excepciones en los procedimientos oficiales provocaban resistencias. Por ende, se violaban las leyes impunemente porque no había la debida autoridad en quienes debían hacerla cumplir ${ }^{58}$.

La norma se incumplía y algunas inspecciones revestían parcialidad. La primera vez que NE hizo esa denuncia fue en febrero de 1925. Tras recibir una comunicación del DPT informando sobre cuatro infracciones a la ley, el diario decidió no informar los nombres de los multados. En el trayecto que mediaba entre los negocios afectados los inspectores no habían entrado a otros comercios donde tampoco se cumplía la ley. El inspector del organismo había sido conducido a los negocios por los empleados de Policía, que antes habían informado a la mayoría de los que vendían bebidas que se pusieran "en guardia" porque estaban en la ciudad aquellos funcionarios ${ }^{59}$. Los inspectores no residían en la ciudad, pero sus

56 "Desde el domingo se hará cumplir estrictamente la ley de descanso dominical en Tandil. En ese sentido se ha recibido en la comisaría una incitación del Ministerio de Gobierno", Nueva Era, Tandil, 21 de diciembre, 1928, 1.

57 "Departamento del Trabajo. Han sido multados numerosos comerciantes e industriales de Tandil", Nueva Era, Tandil, 24 de diciembre, 1928, 2.

58 "Persiguiendo el cumplimiento de la ley de descanso dominical", Nueva Era, Tandil, 18 de junio, 1929, 1.

59 "Departamento del Trabajo de la Provincia de Buenos Aires", Nueva Era, Tandil, 17 de febrero, 1925, 2. 
actividades estaban mediadas por actores que sí lo hacían, lo que destaca la importancia de los vínculos interpersonales (de vecindad, amistad, etc.), que también intervenían a la hora de aplicarse la ley. Por ende, la mayor o menor vigilancia de la norma también se relacionaba con los funcionarios policiales que vigilaban su cumplimiento cuando no estaban los inspectores del DPT; y allí es importante destacar los posibles intereses puestos en juego (económicos, políticos, etc.) señalados por la prensa; pero también rescatar los ya aludidos vínculos sociales, familiares y vecinales, en especial en una comunidad relativamente pequeña como lo era Tandil en la década de 1920. Así, por ejemplo, en diciembre de 1923 NE señalaba que antes de esa fecha la Policía había controlado la aplicación de la Ley 3.098, pero el control había disminuido tras cambiar el jefe policial ${ }^{60}$.

Tras el golpe de Estado de septiembre de 1930 la Ley 3.098 continuaría sin aplicarse en forma plena en la ciudad. En octubre de 1930 la SEC envió una nota a la Cámara Comercial e Industrial de Tandil señalando que las leyes obreras eran violadas por parte de los patrones asociados, mientras otros las acataban ${ }^{61}$. Por su parte, la Cámara Comercial e Industrial les recordaba a sus asociados que el DPT había impartido órdenes para que se observaran estrictamente las disposiciones legales sobre el cierre de los negocios los días domingo ${ }^{62}$. Las disputas entre obreros y patrones continuarían suscitándose a lo largo de la década de 1930 en torno a su cumplimiento.

\section{ConClusión}

A inicios de la década de 1920 en los conflictos obrero-patronales además del DNT comenzó a intervenir el gobierno provincial a través del DPT. Su incidencia a nivel local parece haber sido más importante de lo que se ha sostenido. Dio a conocer nuevas leyes laborales y vigiló su cumplimiento,

60 "El descanso dominical", Nueva Era, Tandil, 7 de diciembre, 1923, 1.

61 "Nota elevada por la Sociedad Empleados de Comercio a la Cámara Comercial e Industrial de Tandil”, Nueva Era, Tandil, 11 de octubre, 1930, 3.

62 "Cámara Comercial e Industrial de Tandil. Descanso dominical", Nueva Era, Tandil, 4 de noviembre, $1930,2$. 
beneficiando a numerosos obreros ${ }^{63}$, si bien en un contexto con fuertes limitaciones presupuestarias y de escaso personal su rol fue limitado.

Los reclamos por una mayor aplicación de la Ley de Descanso Dominical en la década de 1920 presentan aspectos relevantes. En principio, la relación dispar de los funcionarios provinciales con aquellos que no aceptaban aplicarla; mientras que los inspectores del DPT que en forma irregular llegaban a Tandil imponían multas a los infractores, la Policía en ocasiones les colaboraba para que eso no aconteciera y que la Ley siguiera sin cumplirse. Por otro lado, las quejas también manifestaban la persistencia de prácticas arraigadas y difíciles de erradicar; así, la recurrente oposición de los patrones peluqueros a cerrar sus establecimientos los domingos en la mañana se explica al considerarse que solo era en ese momento cuando sus clientes, muchos de ellos trabajadores, podían concurrir. O las quejas de los dueños de bares, esquinas y pulperías, en tanto la sociabilidad tanto en la ciudad como en la campaña se manifestaba los días domingo; así, la finalidad moral que podía tener la norma al pretender dificultar que trabajadores y demás parroquianos consumieran alcohol, entraba en tensión con las prácticas que usufructuaban ese día tradicionalmente dedicado al ocio.

Desde la prensa local se solicitó permanentemente una mayor presencia del DPT. Eso denota que su organización centralizada en La Plata no lograba resolver las problemáticas laborales provinciales; en especial, en el ámbito rural más que en el urbano, dadas las diferencias establecidas desde la ley en relación con su alcance si el afectado era un trabajador urbano o trabajador rural; y las dificultades para ejercer esa vigilancia en el ámbito rural (por las distancias, las dificultades que presentaban los medios de transporte y de comunicación, o la escasa presencia de funcionarios encargados de vigilar las normas). Además, la demanda de su presencia por

63 Lo que hemos podido observar a partir de otros indicadores; así por ejemplo, entre agosto de 1921 y septiembre de 1930 la prensa local permite observar que, tras la intervención del DPT, patrones y compañías de seguros debieron pagar por indemnización de accidentes de trabajo a 26 obreros la suma de 42.600 pesos; también observamos el incremento de las multas que por no cumplir con las leyes laborales debieron pagar los patrones que no cumplían con aquellas leyes, multas que fueron creciendo a medida que el DPT complejizaba su estructura en la década de 1920. 
parte de actores sociales heterogéneos (empleados de comercio, periodistas locales, o funcionarios locales y provinciales) expone una importante validación y aceptación del organismo por parte de la sociedad civil. Es sugerente que a nivel sindical los más interesados en que se cumpliera esta ley (y luego la de la jornada legal de trabajo de ocho horas) hayan sido los empleados de comercio. En Tandil no hemos hallado que otras sociedades obreras propusieran formalmente vigilar el cumplimiento de aquella ley, siendo la SEC el sindicato que denunciaba al DPT sus infracciones.

Sin duda el Estado bonaerense tuvo un importante rol como difusor de las nuevas leyes obreras, si bien como ya se mencionó, la vigilancia de su cumplimiento se vio limitada por factores internos y externos a la propia dinámica del organismo y del contexto histórico en el que se inició su accionar. En la década de 1920 el DPT comenzó a influir sobre las relaciones obrero-patronales del interior provincial. Dicha influencia se profundizaría en la siguiente década, al expandirse su estructura a nivel espacial e institucional, y al intervenir sobre nuevas instancias. La creación de un cuerpo más nutrido de inspectores haría más difícil no cumplir con la Ley de Descanso Dominical, si bien continuarían los debates en el interior de la provincia sobre su cumplimiento.

Pero el DPT no era el único actor que intervenía en la aplicación de la ley. Patrones, empleados de comercio, la prensa local, la Policía, trabajadores urbanos y rurales, así como asociaciones que representaban distintos intereses patronales y obreros, exponían la existencia de diferentes móviles e intereses a la hora de discutirse sobre la esencia y la necesidad de la Ley de Descanso Dominical, en las cuales seguramente jugaban un rol importante las redes políticas que aproximaban y alejaban a funcionarios, agentes policiales, representantes de la prensa, etc.

A partir de una mirada local como la desarrollada en estas páginas, creemos que se puede analizar mejor la incidencia del DPT en el interior provincial, dando cuenta de dimensiones locales pocas veces ensayadas en la historiografía, en su cruce con la esfera de la aplicación de la ley. Dicha perspectiva complementa la perspectiva tradicional construida a partir de lo que aconteció en la capital provincial (La Plata). Como se ha podido 
señalar aquí, la diferencia entre ambos espacios explica también la naturaleza específica de las problemáticas obreras del interior bonaerense, que debieron lidiar con una menor presencia de las autoridades provinciales y nacionales, un respeto patronal a los acuerdos establecidos más reducido, la convivencia de actividades rurales y urbanas, y una menor vigilancia y aplicación de las leyes obreras.

\section{Bibliografía}

\section{Fuentes primarias}

\section{Publicaciones periódicas}

Honorable Cámara de Diputados de la Nación. "Descanso Dominical". Diario de Sesiones de la Cámara de Diputados, Buenos Aires, 26, 28 y 30 de septiembre, 1904, 546-628.

Ministerio de Justicia e Instrucción Pública. "Ley de descanso dominical". Boletín Oficial de la República Argentina, Buenos Aires, 9 de septiembre, 1905, 1.

"Cuatrerismo". El Eco de Tandil, Tandil, 17 de septiembre, 1919.

"El descanso dominical. Decretos reglamentarios". Nueva Era, Tandil, 12 de abril, 1921.

“Descanso dominical”. El Eco de Tandil, Tandil, 28 de abril, 1921.

"Multa a patrones que no cumplen la ley de descanso dominical". Nueva Era, Tandil, 3 de julio, 1922.

"Descanso dominical. Varios comercios multados". Nueva Era, Tandil, 3 de enero, 1923.

"Departamento del Trabajo de la Provincia. Los comerciantes multados".

Nueva Era, Tandil, 12 de enero, 1923.

“Movimiento Obrero". Nueva Era, Tandil, 20 de junio, 1923.

"Solicitada". Nueva Era, Tandil, 11 de septiembre, 1923.

"El descanso dominical”. Nueva Era, Tandil, 7 de diciembre, 1923.

"Un tema de interés. La facultad de cortar alambrados". Nueva Era, Tandil, 14 de abril, 1924.

"Departamento del Trabajo de la Provincia de Buenos Aires". Nueva Era, Tandil, 17 de febrero, 1925.

“Quejas del pueblo. Dos obreros que no pueden cobrar". Nueva Era, Tandil, 11 de mayo, 1925. 
“Departamento del Trabajo. Ayer entró en vigor la ley que prohíbe el trabajo nocturno de los panaderos". Nueva Era, Tandil, 18 de abril, 1927.

“Centro Empleados de Comercio. Visita de Inspección”. Nueva Era, Tandil, 28 de mayo, 1928.

"Desde el domingo se hará cumplir estrictamente la ley de descanso dominical en Tandil. En ese sentido se ha recibido en la comisaría una incitación del Ministerio de Gobierno". Nueva Era, Tandil, 21 de diciembre, 1928.

"Departamento del Trabajo. Han sido multados numerosos comerciantes e industriales de Tandil”. Nueva Era, Tandil, 24 de diciembre, 1928.

"Persiguiendo el cumplimiento de la ley de descanso dominical". Nueva Era, Tandil, 18 de junio, 1929.

"Departamento del Trabajo. Aplicación de multas a comerciantes de Tandil por infringir la ley de descanso dominical". Nueva Era, Tandil, 25 de junio, 1929.

"Se propicia la creación en esta ciudad de una delegación del Departamento del Trabajo de la Provincia”. Nueva Era, Tandil, 12 de agosto, 1930.

"Nota elevada por la Sociedad Empleados de Comercio a la Cámara Comercial e Industrial de Tandil". Nueva Era, Tandil, 11 de octubre, 1930.

“Cámara Comercial e Industrial de Tandil. Descanso dominical”. Nueva Era, Tandil, 4 de noviembre, 1930.

\section{Libros}

Pérez, Benito. Los accidentes del trabajo en la agricultura. Buenos Aires: Editorial Sociedad Bibliográfica, 1943.

Provincia de Buenos Aires. Departamento del Trabajo de la Provincia de Buenos Aires 1922-1926. La Plata: Taller de Impresiones Oficiales, 1927.

Provincia de Buenos Aires. Registro Oficial de la Provincia de Buenos Aires. Enero-junio de 1916. La Plata: Taller de Impresiones Oficiales, 1917.

República Argentina. Tercer Censo Nacional 1914. Tomo V Explotaciones agropecuarias. Buenos Aires: Talleres Gráficos de L. J. Rosso y Cía., 1919. 


\section{Web}

Ministerio de Gobierno de la Provincia de Buenos Aires, eds. Legislación bonaerense. La Plata, 2010, http://www.gob.gba.gov.ar/intranet/digesto/PDF/ley3098.pdf

\section{Fuentes secundarias}

Ascolani, Adrián. "Orígenes de la legislación laboral agraria en Argentina. Vinculaciones con la política y la economía, 1900-1930". Anuario de la Escuela de Historia No. 16 (1993): 145-161.

Ascolani, Adrián. El sindicalismo rural argentino. Buenos Aires: Universidad Nacional de Quilmes, 2009.

Aspell, Marcela. "La realidad social y la regulación jurídica del descanso dominical, los días festivos, los horarios de trabajo". Cuadernos de Historia No. 12 (2002): 67-84.

Auza, Néstor. "La política del Estado en la cuestión obrera al comenzar el siglo XX: El Departamento Nacional del Trabajo, 1907-1912". Revista de Historia del Derecho No. 15 (1987): 101-140.

Barandiarán, Luciano. "Estado y trabajo. Las políticas públicas y los trabajadores rurales pampeanos en los inicios del Estado "interventor" (1925-1950)". (Tesis de Doctorado en Historia, UNCPBA, 2008).

Béjar, María Dolores. El régimen fraudulento. La política en la provincia de Buenos Aires, 1930-1943. Buenos Aires: Siglo XXI Editores, 2005.

Bitrán, Rafael y Alejandro Schneider,. El gobierno conservador de Manuel A. Fresco en la provincia de Buenos Aires (1936-1940). Buenos Aires: CEAL, 1991.

Campione, Daniel. Orígenes estatales del peronismo. Buenos Aires: Miño y Dávila, 2007.

Caruso, Laura. "La política laboral argentina en la inmediata posguerra: una perspectiva internacional, 1907-1925". Revista Relaciones Vol. 35 No. 138 (2014): 11-43.

Corva, María Angélica y Horacio García Bossio,. "El derecho laboral antes de Perón. Origen del Departamento de Trabajo de la Provincia de Buenos Aires". En Actas de las Primeras Jornadas de Historia Argentina. Hacia el Bicentenario de Mayo. La Plata: Universidad Católica Argentina, 2003, 1-18. 
Cuadrado Hernández, G. "La rebelión de los braceros". Todo es historia No. 18 (1982): 78-95.

Del Campo, Hugo. Sindicalismo y peronismo. Los comienzos de un vínculo perdurable. Buenos Aires: Siglo XXI Editores, 2005 [1983].

Garguin, Enrique. "Relaciones entre Estado y sindicatos durante los gobiernos radicales, 1916-1930". En Argentina: trabajadores entre dos guerras, compilado por José Panettieri. Buenos Aires: Eudeba, 2000, 87-117.

Garzón Rogé, Mariana. "Las relaciones laborales en la mira del Estado provincial de Mendoza". En La sociedad del trabajo. Las instituciones laborales en la Argentina (1900-1955), compilado por Mirta Lobato y Juan Suriano. Buenos Aires: Edhasa, 2013, 131-153.

Gaudio, Ricardo y Jorge Pilone,. "El desarrollo de la negociación colectiva durante la etapa de modernización industrial en la Argentina. 19351943”. Desarrollo Económico Vol. 23 No. 90 (1983): 255-286.

Gaudio, Ricardo y Jorge Pilone,. "Estado y relaciones laborales en el período previo al surgimiento del peronismo, 1935-1943”. Desarrollo Económico Vol. 24 No. 94 (1984): 235-273.

Korzeniewicz, Roberto. "Las vísperas del peronismo. Los conflictos laborales entre 1930 y 1943”. Desarrollo Económico Vol. 33 No. 131 (1993): 323-354.

Landaburu, Alejandra. "Los industriales y el Departamento Provincial del Trabajo ante el conflicto obrero de 1919 en Tucumán”. En La sociedad del trabajo. Las instituciones laborales en la Argentina (19001955), compilado por Mirta Lobato y Juan Suriano. Buenos Aires: Edhasa, 2013, 85-104.

Lobato, Mirta y Suriano, Juan. "Introducción. Trabajo, cuestión social e intervención estatal". En La sociedad del trabajo. Las instituciones laborales en la Argentina (1900-1955), compilado por Mirta Lobato y Juan Suriano. Buenos Aires: Edhasa, 2013, 9-53.

Luciani, María. "La etapa formativa de la Secretaría de Trabajo y Previsión (1943-1946): Primeros pasos organizativos y figuras relevantes". Anuario del Instituto de Historia Argentina No. 14 (2014): 1-16.

Lvovich, Daniel y Juan Suriano, (eds.). Las políticas sociales en perspectiva histórica. Argentina, 1870-1952. Buenos Aires: Prometeo-UNGS, 2006. 
Miguez, Eduardo. "Política, participación, poder. Los inmigrantes en las tierras nuevas de la provincia de Buenos Aires en la segunda mitad del siglo XIX". Estudios Migratorios Latinoamericanos. No. 6/7 (1987): 337-378.

Murmis, Miguel y Juan Carlos Portantiero,. Estudios sobre los orígenes del peronismo. Buenos Aires: Siglo XXI Editores, 2004 [1971].

Nario, Hugo. Los picapedreros. Tandil: Ediciones del Manantial, 1997.

Ortiz Bergia, María José. "El intervencionismo estatal en el espacio provincial. Construcción de políticas laborales en Córdoba, 1930-1943”. Población y Sociedad No. 16 (2009): 151-186.

Ortiz Bergia, María José. "El tratamiento estatal de la "cuestión obrera" en Córdoba, 1930-1943”. En La sociedad del trabajo. Las instituciones laborales en la Argentina (1900-1955), compilado por Mirta Lobato y Juan Suriano. Buenos Aires: Edhasa, 2013, 177-198.

Palacio, Juan Manuel. La paz del trigo. Cultura legal y sociedad local en el desarrollo agropecuario pampeano. 1890-1945. Buenos Aires: Edhasa, 2004.

Palacio, Juan Manuel. "La provincia de Buenos Aires en la historia y en la historiografía". En Historia de la provincia de Buenos Aires. Tomo I, Población, ambiente y territorio, editado por Hernán Otero. Buenos Aires: Unipe-Edhasa, 2012, 9-48.

Palavecino, Valeria. "Comercio rural en la campaña bonaerense. Un estudio de caso: Casa de Comercio "El Progreso" de los Hnos. Vulcano (1922-1932)". Mundo Agrario Vol. 6 No. 12 (2006): 1-20.

Palavecino, Valeria. "Surgimiento de poblados al sur de la provincia de Buenos Aires. El ferrocarril y las poblaciones rurales en el partido de Tandil (1880-1955)". En Segundas Jornadas Nacionales de Historia Social. Córdoba: Centro de Estudios Históricos Prof. Carlos Segreti, 2009,1-27.http:/ / cehsegreti.org.ar/historia-social-2/mesas\%20ponencias/MESA $\% 2012 /$ Ponencia $\% 20$ Valeria $\% 20$ Palavecino.pdf.

Ramacciotti, Karina. “¿Soldados del trabajo o ciudadanos? La Ley de accidentes de Trabajo en la Argentina, 1915-1955”. En La sociedad del trabajo. Las instituciones laborales en la Argentina (1900-1955), compilado por Mirta Lobato y Juan Suriano. Buenos Aires: Edhasa, 226 2013, 293-317.

Reitano, Emir. Manuel A. Fresco, antecedentes del gremialismo peronista. Buenos Aires: CEAL, 1992. 
Rock, David. El radicalismo argentino, 1890-1930. Buenos Aires: Amorrortu, 2001.

Sartelli, Eduardo. "De estrella a estrella... De sol a sol... Huelgas de braceros en Buenos Aires, 1918-1922". En Conflictos obreros-rurales pampeanos (1900-1937), tomo I, compilado por Waldo Ansaldi. Buenos Aires: CEAL, 1993.

Scheinkman, Ludmila. "Sujetos, instituciones y derechos en la implementación de la Ley de Accidentes del Trabajo en la ciudad de Buenos Aires (1915-1922)". Estudios Sociales. No. 49 (2015): 125-154.

Soprano, Germán. "El Departamento Nacional del Trabajo y su Proyecto de Regulación Estatal de la Relación Capital-Trabajo en Argentina: 1907-1943”. En Argentina: trabajadores entre dos guerras, compilado por José Panettieri. Buenos Aires: Eudeba, 2000, 31-53.

Soprano, Germán.. "Del Estado en singular al Estado en plural. Contribución para una historia social de las agencias estatales en la Argentina”. Cuestiones de sociología No. 4 (2007): 19-48.

Soprano, Germán "Haciendo inspección. Un análisis del diseño y aplicación de la inspección laboral por los funcionarios del Departamento Nacional del Trabajo (1907-1914)". En Un Estado con rostro humano. Funcionarios e instituciones estatales en Argentina (desde 1880 a la actualidad), editado por Ernesto Bohoslavsky y Germán Soprano. Buenos Aires: Prometeo, 2010, 85-120.

Suriano, Juan. "El Estado argentino frente a los trabajadores urbanos: política social y represión, 1880-1916”. Anuario de la Escuela de Historia No.14 (1989): 109-136.

Suriano, Juan. "El Departamento Nacional del Trabajo y la política laboral durante el primer gobierno de Hipólito Yrigoyen”. En Los saberes de Estado, compilado por Mariano Ben Plotkin y Eduardo Zimmermann. Buenos Aires: Edhasa, 2012, 35-62.

Suriano, Juan. "El mundo como un taller de observación. La creación del Departamento Nacional del Trabajo y las influencias internacionales”. Revista de Indias, Vol. LXXIII No. 257 (2013): 107-130.

Torre, Juan Carlos. "Transformaciones de la sociedad argentina”. En Argentina 1910-2010. Balance del siglo, editado por Roberto Russell. Buenos Aires: Taurus, 2010, 167 a 225. 
Velázquez, Guillermo. Población y empleo en el partido de Tandil (19141985). Tandil: Municipalidad de Tandil-UNCPBA, 1989.

Velázquez, Guillermo, Diana Lan, , y Graciela Nogar,. Tandil a fin del milenio. Una perspectiva geográfica. Tandil: CIG-FCH UNCPBA, 1998.

Velázquez, Guillermo. "La dinámica de la población tandilense: el marco histórico-geográfico". En Tandil a fin de milenio: una perspectiva geográfica, compilado por Guillermo Velázquez, Diana Lan y Graciela Nogar. Tandil: CIG/FCH/UNCPBA, 1998, 61-79.

Zimmermann, Eduardo. Los liberales reformistas. La cuestión social en la Argentina (1890-1916). Buenos Aires: Editorial Sudamericana- Universidad de San Andrés, 1995.

Para citar este artículo: Barandiarán, Luciano Oscar. "La intervención estatal en el mundo del trabajo: la aplicación de la Ley de Descanso Dominical en el centro bonaerense (Tandil, 1917-1930)", Historia Caribe Vol. XII No. 31 (Julio-Diciembre 2017): 195-228. DOI: http://dx.doi. org/10.15648/hc.31.2017.7 